\title{
Bilateral Distribution of Oxytocinase Activity in the Medial Prefrontal Cortex of Spontaneously Hypertensive Rats with Experimental Hemiparkinsonism
}

\author{
Manuel Ramírez ${ }^{1}$ et al. * \\ 1 Unit of Physiology, Department of Health Sciences, University of Jaén, Jaén, \\ Spain
}

\section{Introduction}

Oxytocin and vasopressin are important modulators of diverse social and anxiety-related behaviors (Insel, 2010). The enzyme that regulates the function of both peptides, called oxytocinase (OX) or vasopressinase, is also involved in cognitive functions (Stragier et al., 2008; Banegas et al., 2010). Normotensive male Wistar rats exhibited a marked left predominance of OX in the medial prefrontal cortex (mPFC), an area implicated in cognitive functions and reward-related mechanisms in the rat brain and characterized by its asymmetrical organization. Brain dopamine (DA) content as well as the functions in which this neurotransmitter is involved, are asymmetrically organized in physiologic conditions (reviewed by Ramírez et al., 2004). Therefore, Parkinson's disease (PD) represents a disruption of this bilateral pattern of brain DA. Indeed, the disease normally begins unilaterally in the early stages. Animals with hemi-parkinsonism, induced by unilateral nigrostratal lesions using 6-hydroxydopamine (6-OHDA), showed several behavioral abnormalities, not only linked to a disruption of the normal bilateral distribution of brain DA, but probably also by the alteration of other factors such as the disruption of the striking basal left predominance of OX observed in both the left and right sham controls. The bilateral distribution in lesioned animals was altered differently depending on the injured hemisphere. These results may reflect changes in the levels of oxytocin and vasopressin in the mPFC and consequently in the functions in which they are involved and might account, in part, for the cognitive abnormalities observed in hemi-parkinsonism (Henderson et al., 2003). The spontaneously hypertensive rat (SHR), is a recognised model for studies of hypertension. This strain of rat also display major symptoms of the attentiondeficit/hyperactivity disorder (ADHD) such as deficits in attention, impulsivity and hyperactivity when compared to Wistar-Kyoto rats (Russell, 2007). Indeed, SHR have been shown to have also disturbances in the dopaminergic system (Russell, 2007). The aim of this

\footnotetext{
*Inmaculada Banegas ${ }^{1}$, Ana Belén Segarra ${ }^{1}$, Rosemary Wangesteen ${ }^{1}$, Marc de Gasparo², Raquel Durán ${ }^{3}$, Francisco Vives ${ }^{3}$, Antonio Martínez ${ }^{1}$, Francisco Alba ${ }^{3}$ and Isabel Prieto ${ }^{1}$

${ }^{2}$ Rue es Planches 5, 2842 Rossemaison, Switzerland.

'Instituto de Neurociencias 'Federico Oloriz', University of Granada, Granada, Spain.
} 
study was to analyze OX in the left and right mPFC of SHR with left or right hemiparkinsonism, induced by intrastriatal injections of 6-OHDA, and compared with sham controls. The results dramatically differed from those obtained in Wistar normotensive rats. SHR demonstrated a slighter basal left predominance of OX, only significant in left sham controls. The bilateral distribution in lesioned animals was differently altered depending on the injured hemisphere but in a way dissimilar to the one observed in Wistar. Thus, the hemi-parkinsonism induced in animals with cognitive and behavioral abnormalities such as ADHD induces a different brain bilateral response in OX than the one observed in Wistar. These results suggest that the cognitive consequences of hemi-parkinsonism differed between both Wistar and SHR rats. It is proposed that increased OX in $\mathrm{mPFC}$ is related to decreased cognitive process.

\subsection{Brain asymmetry and cognitive functions}

The brain asymmetry, understood as an anatomical, functional or neurochemical difference between the two hemispheres, is a dynamic phenomenon, modulated by both exogenous and endogenous factors. Increasing evidences suggest that under the anatomical and functional asymmetries underlie neurochemical brain lateralizations. However, the link between these three aspects of the brain asymmetry concept as well its own physiological meaning is not yet well understood (Ramírez et al., 2004). In addition, the impairment of cognitive functions, such as occurs during aging, is linked to vascular dementia (Vallesi et al., 2010; Xu et al., 2008). This is also related to some brain disorders, such as PD or ADHD, both characterized by disruptions in the specific physiological bilateral organization of the brain (Ramírez et al., 2004; Banegas et al., 2010; Shaw et al., 2009). Analyzing how brain bilaterality changes in specific conditions may help us to understand its meaning and its importance in physiology and pathology.

\subsection{Brain asymmetry and dopamine function}

Numerous studies of the DA content in the striatum in relationship with the rotation (circling behaviour) that the rats exhibited spontaneously and after drug induction (Zimmerberg et al., 1974; Glick et al., 1974; Shapiro et al., 1986) were performed to attempt to relate a neurochemical asymmetry with a lateralized function in physiologic conditions. Zimmerberg et al. (1974) demonstrated that DA levels in the striatum were significantly higher in the contralateral side to which the rats choose in a T-maze test. The concentration of DA between the two hemispheres differed by $15 \%$. However, when high doses of amphetamine were administrated to the animals, this bilateral difference was increased up to $25 \%$ (Glick et al., 1974). For these and later studies, the model of rotational behaviour in rodents was used and revised by Shapiro et al. in 1986. The animals with 6-OHDA-induced unilateral lesions of the substantia nigra exhibited a circling behavior in response to several drugs. It was postulated that animals rotated mainly contralaterally to the side containing a higher content of DA or a higher number of activate postsynaptic DA receptors. Xu et al., (2005) compared, by quantitative autoradiography, the changes in DA receptor binding in the left and right striatum in rats after unilateral DA depletion. In comparison with control levels, DA $\mathrm{D}_{1}$-like receptor binding in the dorsal striatum was reduced 2 weeks after unilateral lesions of the substantia nigra (SN) with 6-OHDA. Remarkably, $\mathrm{D}_{1}$-like receptor binding was decreased in the ipsilateral striatum following unilateral lesions of either the left or right SN. Also, the left and right striatum responded similarly to unilateral SN lesions, as there were no significant differences in the percent decrease in $\mathrm{D}_{1}$-like binding in 
the two striata. In contrast, $\mathrm{D}_{2}$-like receptor binding was significantly increased in the dorsal striatum following an ipsilateral $\mathrm{SN}$ lesion. Furthermore, the up-regulation of $\mathrm{D}_{2}$-like receptors in the right striatum was significantly greater than that in the left striatum after an ipsilateral lesion. The authors speculated that the asymmetrical up-regulation of striatal $\mathrm{D}_{2}$ receptors after DA depletion may contribute to the lateralization of the nigrostriatal system observed in some pathological conditions.

\subsection{Parkinson's disease, brain asymmetry and cognitive functions}

Parkinson's disease is the second most common neurodegenerative disorder (Dorsey et al., 2007). Despite the intensive efforts, progresses in the fight against this disease are slow and new strategies for early diagnosis and treatment to prevent its progression are required (George et al., 2009). A deep knowledge of its pathophysiology is essential to achieve this goal. Although symmetric at the later stages, the damage observed in PD begins asymmetrically (Djaldetti et al., 2006). Therefore, there exist in PD a disruption of the physiologic bilateral distribution of DA content as well as a bilateral disturbance of other neurochemical factors (Banegas et al., 2010). Animal models of PD, such as the experimental hemiparkinsonism after unilateral intrastriatal injections of 6-OHDA, could simulate the initial phase of PD. In the early stages, PD patients exhibit cognitive and behavioral impairments unrelated to the motor symptoms, and involving frontal lobe dysfunction (Brück et al., 2004; Farina et al., 1994; Zgaljardic et al., 2006). They are the result of damage of a specific hemisphere (Cubo et al., 2010). In addition, hemiparkinsonism has been associated with asymmetrical cognitive changes (Huber et al., 1992; Piacentini et al., 2010). Studies in animals with induced hemi-parkinsonism have reported several behavioral abnormalities (Henderson et al., 2003). The mPFC, a part of the mesocorticolimbic system, is involved in cognitive functions and reward-related mechanisms in the rat brain (Tzschentke, 2000). Interestingly, the mesocortical dopamine system, particularly the $\mathrm{mPFC}$, is characterized by its asymmetric organization (Sullivan, 2004).

\subsection{Vascular damage, cognitive impairment and brain asymmetry}

Cerebral capillary damage occurs not only in neurodegenerative disorders such as in Alzheimer's disease and PD but also in hypertension. Thus, it was hypothesized that ultrastructural abnormalities of cerebral capillaries were related to decreased cerebral blood flow that favors neurodegenerative mechanisms leading to the development of dementia (Farkas et al., 2000). Clearly, hypertension is involved in the development of vascular cognitive impairment and vascular dementia (Amenta et al., 2003). Indeed, an impairment of cognitive functions was described in elderly hypertensive individuals (Vinyoles et al., 2008) as well as in childhood (Adams et al., 2010). The SHR is a recognized animal model of cognitive decline associated with hypertension (Diana, 2002). These animals present abnormal dopaminergic transmission and altered neuronal dendrite morphology of the mPFC (Sánchez et al., 2011). Therefore, there exists a connection between hypertension, vascular dementia, cognitive impairment and a modification of the basal brain asymmetry (Xu et al., 2008; Vallesi et al., 2010; Bergerbest et al., 2009).

In the ADHD, characterized by impaired sustained attention, impulsivity and hyperactivity, a disruption of the physiological cortical asymmetry has been implicated in its pathogenesis (Shaw et al., 2009). The SHR, largely used as a model for hypertension, also display major symptoms of the ADHD (Russel, 2007) when compared with normotensive rats. Indeed, 
SHR have also disturbances in the dopaminergic system. Therefore, it could be hypothesized that their brain bilateral functioning for cognitive processes may differ from the brain bilateral behaviour of normotensive rats.

\subsection{Oxytocin, oxytocinase, cognitive functions and brain asymmetry}

It was proposed that systems other than the dopaminergic pathway may also be involved in the behavioral abnormalities observed in PD (Lang \& Obeso, 2004; Banegas et al., 2010). Oxytocin and vasopressin as well as the enzyme that regulates their functions, called oxytocinase (OX) or vasopressinase are involved in cognitive functions. Normotensive male Wistar rats exhibit a marked left predominance of OX in the $\mathrm{MPFC}$, an area implicated in cognitive functions and reward-related mechanisms in the rat brain and characterized by its asymmetrical organization as already mentioned (Sullivan, 2004). Changes in this basal pattern of bilateral organization may cause disorders in brain function (Ramírez et al., 2004). Normotensive animals with hemi-parkinsonism induced by unilateral nigrostratal lesions using 6-OHDA showed several behavioral abnormalities and a disruption of the striking basal left predominance of OX as observed in both the left and right sham controls. The bilateral distribution in lesioned animals was altered differently depending on the injured hemisphere. These results may reflect changes in the levels of oxytocin and vasopressin in the $\mathrm{mPFC}$ and consequently, in their functions. This could account, in part, for the cognitive abnormalities observed in hemi-parkinsonism (Banegas et al., 2010).

Therefore, considering that background, it was indicated to analyze OX in the left and right mPFC of SHR with left or right hemi-parkinsonism, induced by intrastriatal injections of 6OHDA, and compare its activity in sham SHR controls. These results will be discussed with those obtained previously in normotensive rats using the same protocol (Banegas et al., 2010). This approach should give precious indications on the behavior of brain bilaterality in two strains of rat that clearly differ in their cognitive status.

\section{Materials and methods}

\subsection{Animals}

Three-month-old male SHR (systolic blood pressure: $164.1 \pm 4.2 \mathrm{mmHg} ; \mathrm{n}=40$ ) weighing 250 $\mathrm{g}$ at the beginning of the study were used for both sham and lesioned groups. During the experimental period, food and water were available ad libitum. The animals were housed under standard conditions of light $(12 \mathrm{~h}$ of light from $7.00 \mathrm{~h}$ to $19.00 \mathrm{~h}$ and $12 \mathrm{~h}$ of dark from $19.00 \mathrm{~h}$ to $7.00 \mathrm{~h})$ and temperature $\left(22^{\circ} \mathrm{C}\right)$.

\subsection{Surgical procedure}

Degeneration of the left or right nigrostriatal dopaminergic pathway was accomplished via neurochemical lesions induced with the catecholaminergic toxin 6-OHDA (Jolicoeur and Rivest, 1992). All animals were anesthetized with $2 \mathrm{ml} / \mathrm{kg}$ body weight equithensin (42.5 $\mathrm{g} / \mathrm{L}$ chloralhydrate dissolved in $19.76 \mathrm{~mL}$ ethanol, $9.72 \mathrm{~g} / \mathrm{L} \mathrm{Nembutal}{ }^{\circledR}, 0.396 \mathrm{~L} / \mathrm{L}$ propylenglycol and $21.3 \mathrm{~g} / \mathrm{L}$ magnesium sulfate in distilled water) and placed in a stereotaxic instrument (David Kopf Instruments, Palo Alto, CA, USA). A 2 mm burr hole was drilled through the skull at horizontal coordinates approximating the position of the striatum (AP $0 \mathrm{~mm}$, L or $\mathrm{R} 3 \mathrm{~mm}$ and $\mathrm{H}-5 \mathrm{~mm}$ ) according to the atlas by Paxinos and Watson (1998). Infusion of $4 \mu \mathrm{L}$ of 6-OHDA (8 mg dissolved in $1 \mathrm{~mL}$ of cold saline with $0.02 \%$ ascorbic acid to inhibit oxidation) was administered into the left or right striatum 
(Jolicoeur \& Rivest, 1992). The control rats were operated the same manner but they received $4 \mu \mathrm{l}$ of saline with $0.02 \%$ ascorbic acid.

\subsection{Motor behaviour in experimental hemiparkinsonism}

Normal rats exhibit a spontaneous turning behaviour, the levels of DA being higher in the contralateral striatum than the side of the turning preference (Glick, 1983). Therefore, animals with experimental hemiparkinsonism turn ipsilaterally to the side of lesion. This turning behavior was amplified after amphetamine administration that increases dopamine in the synaptic cleft. Assessment of the ipsilateral rotational behavior allowed us to verify the efficacy of the 6-OHDA-induced lesions. Four weeks post-surgery and three days before sacrifice, animals were given D-amphetamine sulfate $(5 \mathrm{mg} / \mathrm{kg}$ s.c.) to enhance the turning behaviour (Robinson et al., 1994) while placed in a $30 \mathrm{~cm}$ diameter bowl. Number of turns was determined in 6 periods of $10 \mathrm{~min}$. during $1 \mathrm{~h}$. Sufficiently rotating animals were included in lesion group. Sham-lesioned rats underwent the same surgery and rotational testing but did not demonstrate sufficient rotational behaviour to qualify as parkinsonian models. Most animals exceeded the $100 \%$ of turns from mean of control and were considered with hemiparkinson. Lesioned animals that did not presented turning behaviour but exhibited rigidity after D-amphetamine injection also were considered with hemiparkinson. Compared with sham controls, a marked ipsilateral rotational behavior was observed in left- and right-lesioned animals (Banegas et al., 2009) (figure 1).

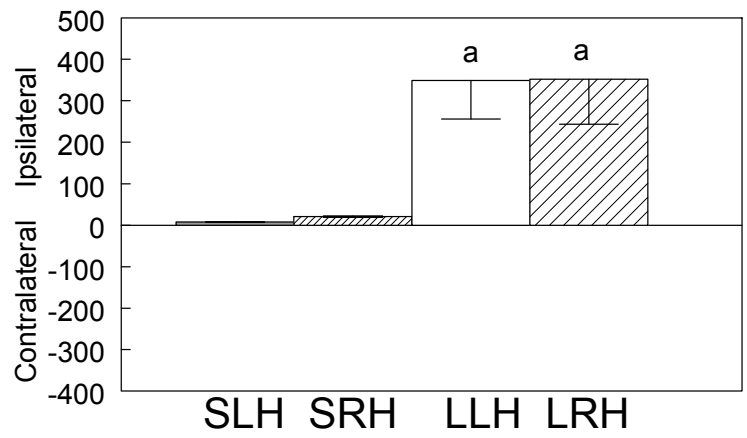

Fig. 1. Turning behaviour in the groups studied.

Turning behaviour in lesioned left (LL) or lesioned right (LR) and sham left (SL) or sham right (SR) spontaneously hypertensive rats $(\mathrm{H})$. Number of turns were determined individually in 6 periods of 10 min during $1 \mathrm{~h}$. Values represent mean \pm SEM $(n=10)$ of the cumulative turns recorded in the 6 periods (modified from Banegas et al., 2009 with permission). a Differences between the same side of lesioned vs sham animals. a $\mathrm{p}<0.001$

\subsection{Collection and treatment of tissue samples}

The surgical procedure, sacrifice and sample collection were performed under anesthesia between $9.00 \mathrm{~h}$ and $11.00 \mathrm{~h}$. Four weeks after receiving the injections, the animals were sacrificed and mPFC samples were obtained from each group as previously described (Banegas et al, 2005a). Briefly, the animals were perfused with saline transcardially under equithensin anaesthesia (2 ml/ $\mathrm{kg}$ body weight). The brain was quickly removed (less than 
$60 \mathrm{~s})$ and cooled in dry ice. Left and right brain samples were dissected according to the stereotaxic atlas of Paxinos \& Watson (1998). The selected area of mPFC was between 12,70 $\mathrm{mm}$ and 11,70 $\mathrm{mm}$ anterior to the interaural line. All samples were collected the same day and frozen for assays. Tissue samples were homogenized in $400 \mu \mathrm{l}$ of $10 \mathrm{mM} \mathrm{HCl}$-Tris buffer $(\mathrm{pH} 7,4)$ and ultracentrifugated at $100,000 \times \mathrm{g}$ for $30 \mathrm{~min}$. at $4{ }^{\circ} \mathrm{C}$. The pellets were rehomogenized in $\mathrm{HCl}$-Tris buffer $(\mathrm{pH} 7,4)$ plus $1 \%$ Triton-X-100 to solubilize membrane proteins. After centrifugation $\left(100,000 \times \mathrm{g}, 30 \mathrm{~min} ., 4^{\circ} \mathrm{C}\right.$ the supernatants were shaked in an orbital rotor during $2 \mathrm{~h}$. at $4{ }^{\circ} \mathrm{C}$ with the polymeric adsorbent Bio-Beads SM-2 $(100 \mathrm{mg} / \mathrm{ml})$ in order to remove the detergent from the sample (Alba et al., 1995). The bio-beads were removed and the supernatants were used to measure in triplicate membrane-bound aminopeptidase activities and protein content. Left or right 6-OHDA-lesioned animals were compared with their corresponding left or right sham-operated animals in which the DA pathways were intact. Because bilateral injuries usually lead to the death of rats due to the occurrence of marked aphagia and adipsia (Ungerstedt, 1971), such control animals were not available.

\subsection{Procedures for enzymatic assays}

Membrane-bound oxytocinase activity was measured fluorometrically using L-Cys- $\beta$ naphthylamide as previously described (Banegas et al., 2005a). Proteins were quantified in triplicate by the method of Bradford (1976) using BSA as a standard. Specific OX was expressed as nanomoles of L-Cys- $\beta$-naphthylamide hydrolyzed per minute per milligram of protein. Fluorogenic assays were linear with respect to the time of hydrolysis and protein content.

\subsection{Experimental groups}

Oxytocinase activity levels were measured in mPFC of the following groups $(n=10$ for all groups):

a. Simulated lesion of the left hemisphere with saline (sham left, SL)

b. Simulated lesion of the right hemisphere with saline (sham right, SR)

c. Lesion of left hemisphere with 6-OHDA (lesion left, LL)

d. Lesion of right hemisphere with 6-OHDA (lesion right, LR)

All experimental procedures involving animals, including their use and care, were in accordance with the European Communities Council Directive 86/609/EEC.

\subsection{Statistical analysis}

We used a one-way analysis of variance (ANOVA) to analyze differences between groups. Post-hoc comparisons were made using the paired Student's $t$ test; p-values below 0.05 were considered significant.

\section{Results}

Results of the present research are represented in figures 2 and 3. There was an asymmetry of OX in the $\mathrm{mPFC}$ of left controls (SL) showing a significant left predominance (41\% higher; $\mathrm{p}<0.01)$. The right controls (SR) showed a tendency for left predominance $(15 \%$ higher $)$ without reaching statistical significance. After left lesion (LL), there was an increased left 
predominance $(75 \%$ higher; $\mathrm{p}<0.001)$, whereas the OX predominance shifted slightly to the right hemisphere in right lesioned animals (LR) $(19 \%$ higher; $\mathrm{p}<0.05)$ (fig. 2).

Compared with the same side of sham animals, the LL produced a significant increase in OX in the left $\mathrm{mPFC}(48 \%$ higher; $\mathrm{p}<0.01)$ and no modification in the right side. The LR decreased OX in the left $\mathrm{mPFC}(32 \%$ lower; $\mathrm{p}<0.01)$ but did not modify OX activity in the right side compared to the control.

The percentage differences ([(high/low)-1] x 100) between the left and right values of OX in $\mathrm{mPFC}$ for each animal in the four groups are shown in figure 3. In SL and SR, although with low level of percentage, most animals were left predominant. The differences ranged from $11 \%$ to $113 \%$ higher OX activity in the left mPFC of eight SL animals $(\mathrm{p}<0.01)$ and from $4 \%$ to $56 \%$ in seven SR animals (without significant differences between mean values). In LL animals, the level of percentage for left OX predominance increased slightly, ranging from $18 \%$ to $185 \%$ (higher) in eight animals ( $\mathrm{p}<0.001)$. The SHR from the LR group shifted slightly to the right predominance $(\mathrm{p}<0.05)$ with seven animals right predominance ranging from $3 \%$ to $77 \%$.

The present results are indicative of an influence of DA depletion on the bilateral levels of OX in the mPFC of hypertensive rats, and dramatically differ from the data observed in normotensive Wistar rats (Banegas et al, 2010). These effects are conditioned by the side in which 6-OHDA or saline was administered.

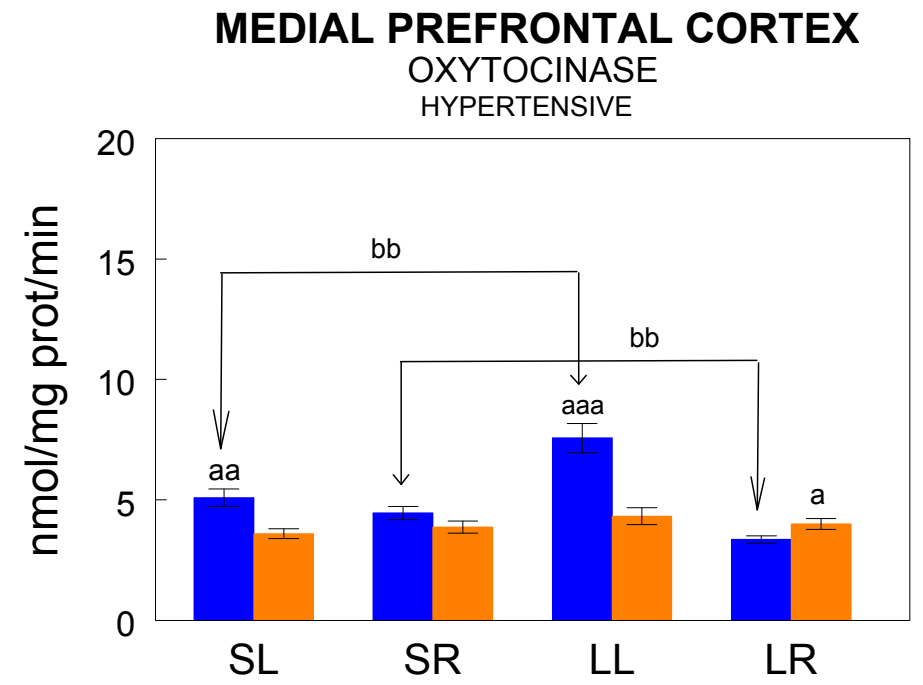

Fig. 2. Oxytocinase activity in the left and right medial prefrontal cortex of hypertensive rats.

Oxytocinase activity in the left (blue bars) and right (rose bars) medial prefrontal cortex of left (SL) or right (SR) sham-operated and left (LL) or right (LR) 6-OHDA lesioned hypertensive rats. ( $\mathrm{n}=10$ in each group). Values represent mean \pm SEM of specific oxytocinase activity expressed as nanomoles of Cys- $\beta$ naphthylamide hydrolyzed per minute per milligram of protein. (a) Differences between left and right sides. (b) Differences in the same side between sham and lesioned animals. Single letter: $p<0.05$; double letter: $\mathrm{p}<0.01$; triple letter: $\mathrm{p}<0.001$. 


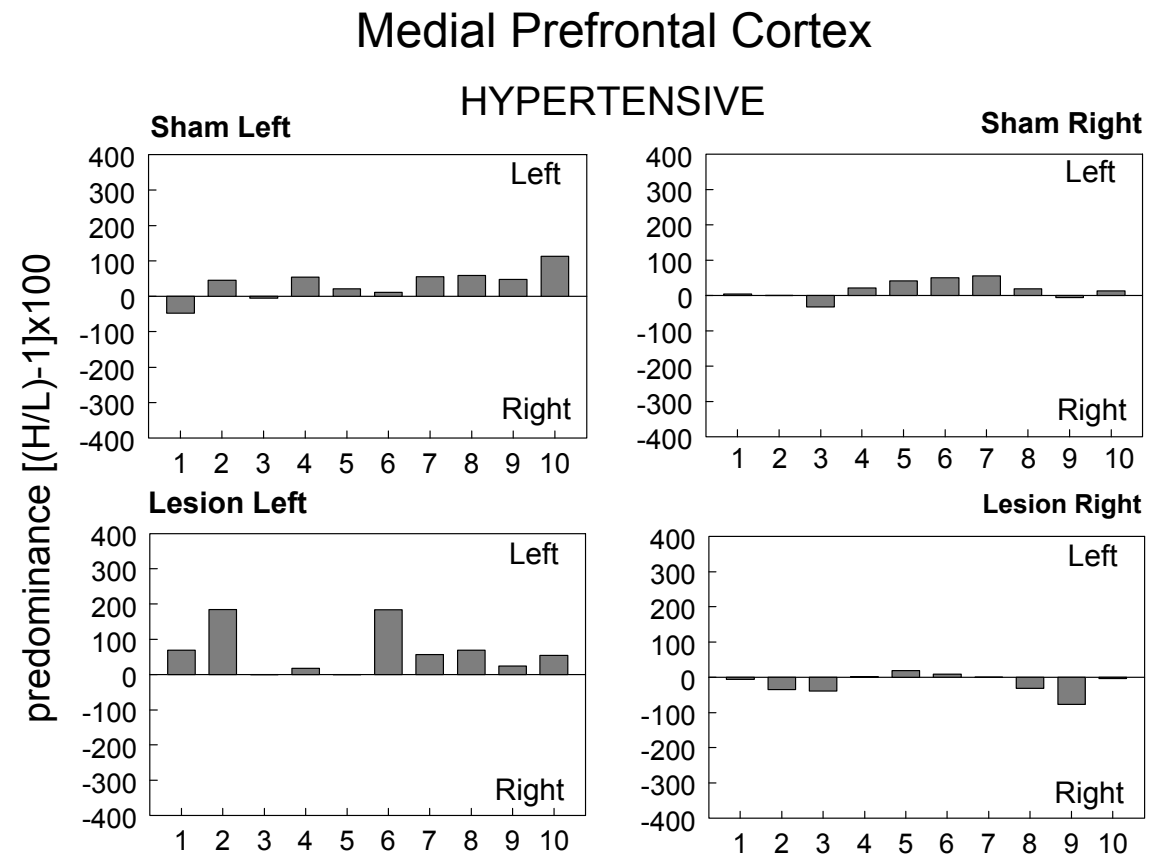

Fig. 3. Percentage differences between the left and right prefrontal cortex of hypertensive rats

Bars represent the percentage differences between the levels of oxytocinase activity of the left and right sides of the prefrontal cortex for each of the hypertensive rats studied in all four groups. $\mathrm{H}$, higher value; $\mathrm{L}$, lower value.

\section{Discussion}

It has been demonstrated that the PFC plays a critical role in the development of ADHD and that the mesocortical DA system is involved in that process. In addition, previous studies demonstrated that the laterality of the prefrontal function in the rat is also involved in ADHD, particularly the dysregulation of the right PFC having a deficit of its dopaminergic system (Sullivan \& Brake, 2003). Indeed, the mPFC DA system exhibits many functional hemispheric asymmetries involving the right mesocortical DA system. Thus, 6-OHDA lesions of the right but not the left frontal cortex conducts to pronounced behavioural hyperactivity and altered subcortical catecholamine function. The right frontal systems play a key role in motor inhibition and the mesocortical DA seems to be an important part of this regulation. It is therefore expected that its impairment may led to hyperactivity behaviour. ADHD children have mainly impaired ability to keep their attention focus due to dysfunctions in the right hemisphere attention systems (Reviewed by Sullivan \& Brake, 2003).

Therefore, it is interesting to compare the bilateral behavior of the mPFC after the specific lesion of the right or the left nigrostriatal dopaminergic system in normotensive rats and in an animal model of ADHD: the SHR strain. This could provide valuable information on the bilateral behaviour of the frontostriatal dopaminergic system whose operation is critical for understanding the pathogenesis of disorders such as PD or ADHD. 
The present results obtained in SHR differed substantially from those previously obtained in normotensive rats (Banegas et al, 2010). Most importantly, there is a remarkable lower level of left predominance in sham hypertensive controls (figures 2 and 3), compared with the high one observed in sham normotensive controls (figures 4 and 5). This is in agreement with the reduction of the asymmetry observed in prefrontal cortex and hippocampus in ADHD (Shaw et al., 2009) and during aging and vascular dementia compared to healthy subjects (Xu et al., 2008; Vallesi et al., 2010; Bergerbest et al., 2009). Indeed, disruption of physiological asymmetry has been involved in the pathogenesis of cognitive disorders such as ADHD. An increase in the thickness of the right frontal cortex together with a lefthemispheric increase in the occipital cortical regions characterize the normal bilateral development of children. However, in ADHD, while the posterior component of this bilateral development was intact, the prefrontal one was lost (Shaw et al., 2009). The morphological asymmetry of hippocampus in healthy subjects, assessed by magnetic resonance imaging, is greater than that in Alzheimer's disease and in patients with vascular dementia (Xu et al., 2008). Studying the effects of age on the asymmetry of the motor system, Vallesi et al. (2010) reported that older adults showed a more symmetric pattern than younger subjects. Moreover, an age-associated reduction of asymmetry in prefrontal function has been related to several forms of cognitive impairment (Bergerbest et al., 2009).

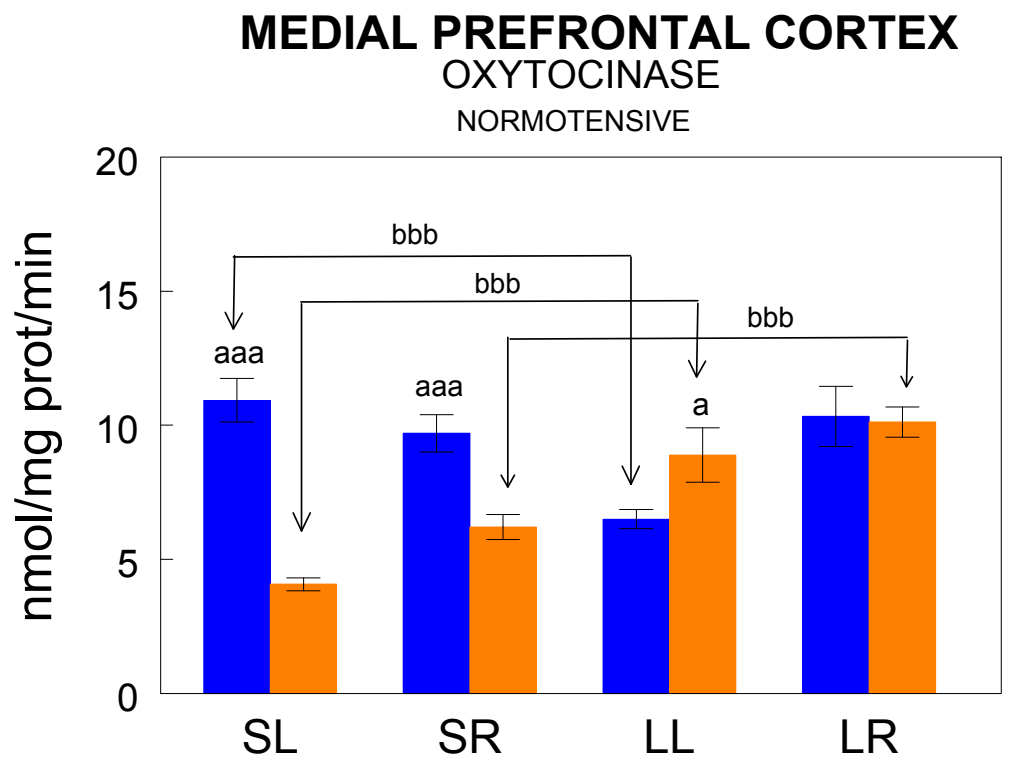

Fig. 4. Oxytocinase activity in the left and right medial prefrontal cortex of normotensive rats

Oxytocinase activity in the left (gray bars) and right (open bars) medial prefrontal cortex of left (SL) or right (SR) sham-operated and left (LL) or right (LR) 6-OHDA lesioned normotensive rats. (n=10 in each group). Values represent mean \pm SEM of specific oxytocinase activity expressed as nanomoles of Cys- $\beta$ naphthylamide hydrolyzed per minute per milligram of protein. (a) Differences between left and right sides. (b) Differences in the same side between sham and lesioned animals. Single letter: $p<0.05$; triple letter: $\mathrm{p}<0.001$ (from Banegas et al, 2010 with permission). 


\section{Medial Prefrontal Cortex}

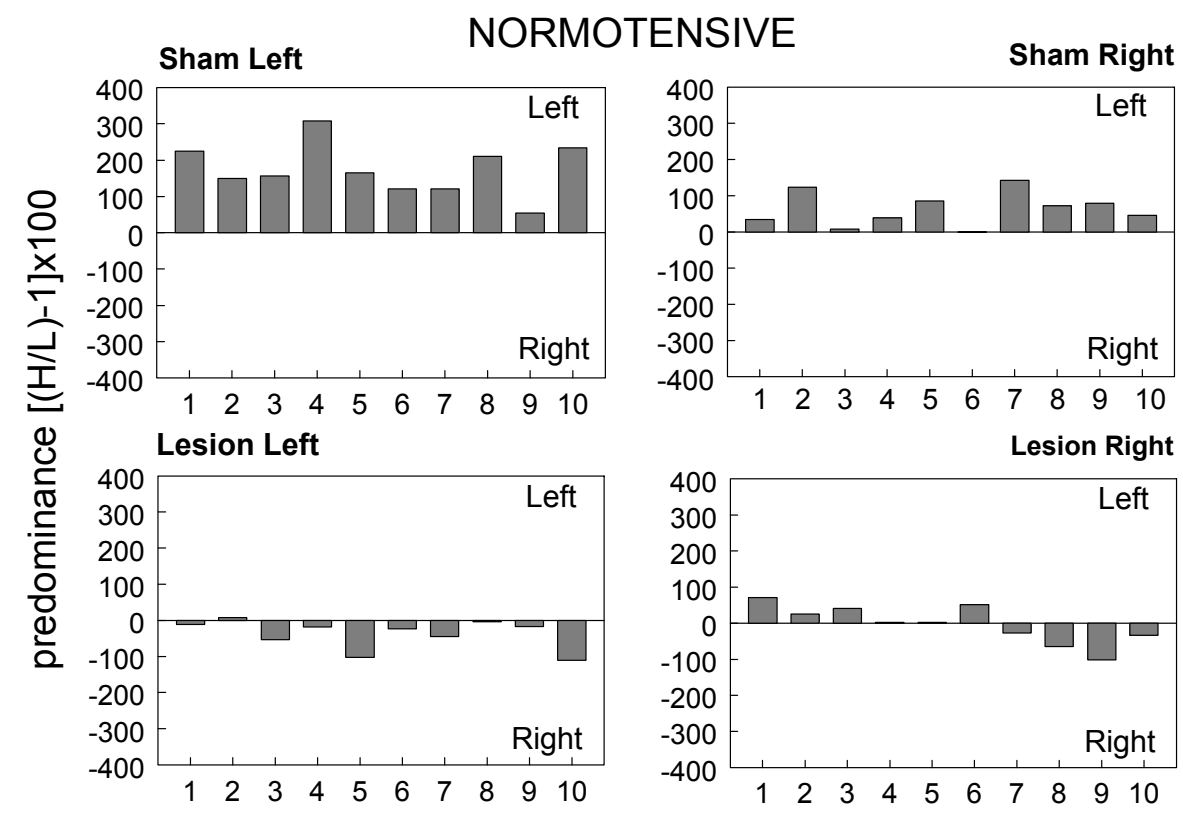

Fig. 5. Percentage differences between the left and right prefrontal cortex of normotensive rats.

Bars represent the percentage differences between the levels of oxytocinase activity of the left and right sides of the prefrontal cortex for each of the normotensive rats studied in all four groups. $\mathrm{H}$, higher value; $L$, lower value.

Especially informative is the comparison of figures 3 and 5 in which we can notice the great difference in the bilateral response of normotensive and SHR. While in SL and SR normotensive rats virtually all the animals were left predominant with a high percentage of difference (figure 5), in SL and SR hypertensive the left predominance is substantially lower (figure 3). Whereas in LL normotensive animals, OX predominance was shifted to the right in nine animals (figure 5), in LL hypertensive rats the left predominance was increased (figure 3). The bilateral response of animals from the LR group of normotensive and hypertensive was quite similar.

The slight difference observed in the bilateral distribution of OX between SL and SR of hypertensive rats could be due to a differential response of the local inflammatory processes following the introduction of the cannula into the left or right hemisphere, as previously suggested by Banegas et al. (2009) in normotensive rats.

The direct effect of lesions in hypertensive animals on OX also differed from the previous observation in normotensive rats. OX decreased in the left side and increased in the right hemisphere of normotensive LL (figure 4). In contrast, in hypertensive LL rats, the enzyme activity increased in the left hemisphere and was not modified in the right one (figure 2).

Clearly, the response to left or right lesions in normotensive rats involved both left and right hemispheres. On the contrary, in hypertensive rats, it only implies changes in the left hemisphere. It is particularly noticeable that the right mPFC was not modified either when left or right lesions were performed, in marked contrast with the important changes that 

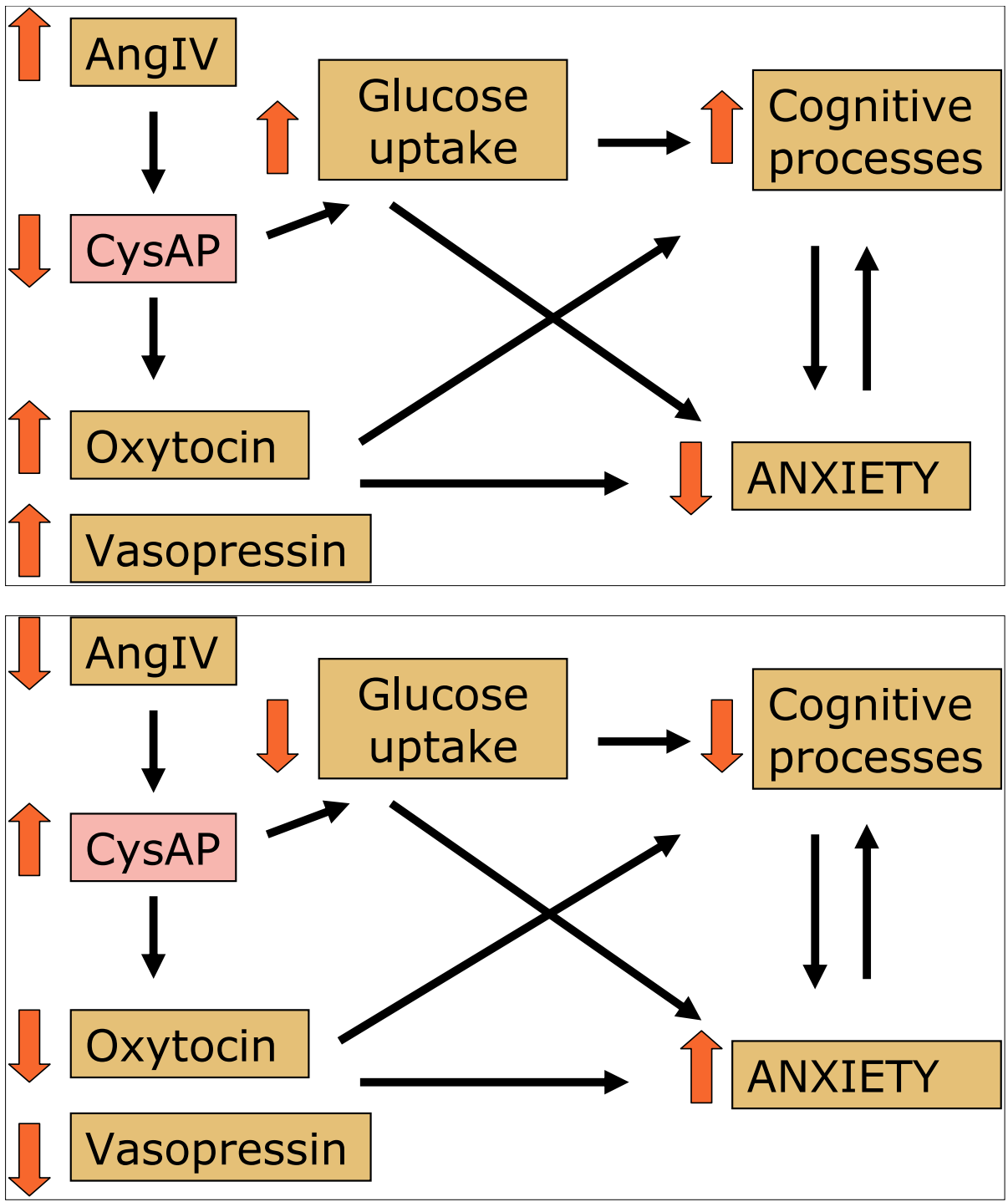

Fig. 6. Hypothetic consequences of frontal changes in CysAP/OX activity

Hypothetic consequences of a reduction (top) or increase (bottom) in the frontal levels of CysAP/OX. Decreased CysAP would imply higher availability of Ang IV as well as lower metabolism/higher availability of its substrates oxytocin and vasopressin. Higher levels of Ang IV could indicate an improvement of cognitive processes (Gard, 2008). The reduction of CysAP may also suggest increased glucose uptake which would also improve cognitive processes (Wenk, 1989). In addition, increased availability of oxytocin or vasopressin would agree with the facilitation of cognitive processes (Gulpinar and Yegen, 2004) as well as a higher anxyolitic effect (Neumann, 2009). Finally, this would support an inverse relationship between cognitive processes and anxiety level (Ouimet et al., 2009). We could suggest contrary effects for an increased frontal level of CysAP. 
occurred in normotensive rats (Banegas et al., 2010). This observation may be linked to the reduced volume of right PFC and reduced metabolism in the MPFC in humans with ADHD (Viggiano et al., 2004).

While ADHD have a reduction of left/right asymmetry, as observed in SL and SR, LL return the asymmetrical difference to a degree similar to that observed in normotensive rats. Accordingly, we could hypothesize that LL but not LR balanced the asymmetrical misbalance of SHR/ADHD.

Angiotensin IV (Ang IV) binds specifically to the $\mathrm{AT}_{4}$ receptor, which is identical to the insulin-regulated aminopeptidase (IRAP) (Albiston et al., 2001). Cystein aminopeptidase (CysAP), also called oxytocinase (OX) or vasopressinase (EC 3.4.11.3), is considered the human variant of IRAP (Stragier et al., 2008). In addition, CysAP was also reported to be identical to the placental leucine aminopeptidase (Tsujimoto et al., 1992). These enzymes can therefore be considered identical and they are located in virtually all regions of the brain, including the cortex (Fernando et al., 2005). In addition, it has been reported that Ang IV increased DA levels in striatum, this effect being mediated by OX/IRAP acting as receptor for Ang IV (Stragier et al., 2007).

Ang IV is thought to play a role in cognitive and behavioral functions. However, the mechanism by which it modulates these functions is not fully understood and several compatible hypothesis have been proposed (Stragier et al., 2008). For example, it was proposed that the binding of Ang IV to its receptor, $\mathrm{AT}_{4}$ (oxytocinase/CysAP/IRAP), results in the inhibition of the receptor's metabolic activity, reducing the catabolism of its substrates and consequently increasing their availability and extending their action (Stragier et al., 2008). Ang IV could therefore regulate glucose uptake modulating OX activity: OX/IRAP is indeed co-localized with the glucose transporter GLUT4. In the presence of insulin, OX and GLUT4 are expressed in the plasma membrane, where GLUT4 induces glucose uptake. It was suggested that the inhibition of OX, following binding of AngIV, could increase glucose uptake in neurons leading to an improvement of cognitive processes (Gard, 2008; Stragier et al., 2008) (figure 6).

In addition to oxytocin, CysAP/OX hydrolyzes vasopressin, enkephalins and other neuropeptides also involved in cognitive processes (Gard, 2008). Indeed, oxytocin and vasopressin are important modulators of diverse social and anxiety-related behaviors (Veenema \& Neumann, 2008). Therefore, a decrease in CysAP/OX activity implies high levels of Ang IV, as well as a lower metabolism and thus a higher availability of its substrates such as oxytocin or vasopressin. Both effects may facilitate cognitive processes (Gard, 2008; Gülpinar \& Yegen, 2004) and reduce anxiety levels (Veenema \& Neumann, 2008). The contrary is occurring in case of an increase in CysAP/OX. Indeed, the development of cognitive enhancers based on the inhibition of OX has been proposed (Chai et al., 2008) (figure 6).

\section{Conclusion}

The present results demonstrated that the bilateral behavior of OX in the MPFC differs between normotensive and hypertensive rats and highlights the importance of bilaterality in biology. The functional meaning of bilaterality as well as how its disruption may lead to pathological consequences are unknown. However, we can speculate that brain functions, processed with varying degrees of asymmetry for the two hemispheres, could be under an universal modus operandi which would consist in the reciprocal inhibition of homologous centers. The regulationof a large number of brain processes is based on a retro-inhibitor- 
stimulator feed-back system. This could explain the existence of neurochemical imbalances that arise, change their side of prevalence or increase their degree of asymmetry in specific conditions. It could be speculated that imbalances in established brain asymmetries (toward symmetry or toward increasing asymmetry) due to unilateral damage, might lead to neuropathological deviations in brain functions (Ramirez et al., 2004; Banegas-Font et al., 2005b) In any case, these results confirm that studies which are not considering the bilaterality may lead to loss of invaluable informations leading to erroneous conclusions and misinterpretations of the pathophysiological processes.

\section{References}

Adams, H.R., Szilagyi, P.G., Gebhardt, L. \& Lande, M.B. (2010), Learning and attention problems among children with pediatric primary hypertension. Pediatrics, Vol. 126, No. 6, (December 2010), pp. 1425-1429. ISSN 0031-4005

Alba, F., Arenas, J.C. \& López, M.A. (1995). Properties of rat brain dipeptidyl aminopeptidases in the presence of detergents. Peptides, Vol. 16, No. 2, pp. 325-329, ISSN 0196-9781

Albiston, A.L., Mcdowall, S.G., Matsacos, D., Sim, P., Clune, E., Mustafa, T., Lee, J., Mendelsohn, F.A., Simpson, R.J., Connolly, L.M. \& Chai, S.Y. (2001), Evidence that the angiotensin IV (AT4) receptor is the enzyme insulin-regulated aminopeptidase. Journal of Biological Chemistry, Vol. 276, No. 52, (December 2001), pp. 48623-48626, ISSN 0021-9258

Amenta, F., Di Tullio, M.A. \& Tomassoni, D. (2003) Arterial hypertension and brain damage - evidence from animal models. Clinical and Experimental Hypertension, Vol. 25, No. 6, (August 2003) pp. 359-380, ISSN 1064-1963

Banegas, I., Prieto, I., Alba, F., Vives, F., Araque, A., Segarra, A.B., Durán, R., de Gasparo, M. \& Ramírez, M. (2005a). Angiotensinase activity is asymmetrically distributed in the amygdala, hippocampus and prefrontal cortex of the rat. Behavioural Brain Research Vol. 156, No. 2, (January 2005) pp. 321-326, ISSN 0166-4328

Banegas Font I, Prieto Gómez I, Araque Cuenca A, Alba Aragüez F, Vives Montero F, Segarra Robles AB, Durán Ogalla R, Ramírez Sánchez MD \& Ramírez Sánchez M. (2005b). [Neurochemical asymmetries in psychiatric alterations] Spanish. Psiquiatría Biológica, Vol.12, No.4, (July 2005) pp. 159-165, ISSN 1134-5934

Banegas, I., Prieto, I., Vives, F., Alba, F., de Gasparo, M., Duran, R., Luna, J de D., Segarra, A.B., Hermoso, F. \& Ramírez, M. (2009). Asymmetrical response of aminopeptidase $\mathrm{A}$ and nitric oxide in plasma of normotensive and hypertensive rats with experimental hemiparkinsonism. Neuropharmacology, Vol.56, No3, (Mars 2009), pp. 573-579, ISSN 0028-3908

Banegas, I., Prieto, I., Vives, F., Alba, F., de Gasparo, M., Duran, R., Segarra, A.B. \& Ramírez, M. (2010). Lateralized response of oxytocinase activity in the medial prefrontal cortex of a unilateral rat model of Parkinson's disease. Behavioural Brain Research, Vol.213, No.2, (December 2010), pp. 328-331, ISSN 0166-4328

Bergerbest, D., Gabrieli, J.D., Whitfield-Gabrieli, S., Kim, H., Stebbins, G.T., Bennett, D.A. \& Fleischman D.A. (2009). Age-associated reduction of asymmetry in prefrontal function and preservation of conceptual repetition priming. Neuroimage. Vol.45, No.1, (Mars 2009) pp.237-246, ISSN 1053-8119

Bradford, M.M. (1976). A rapid and sensitive method for the quantification of microgram quantities of protein utilizing the principle of protein dye binding. Analytical Biochemistry Vol.72, (May 1976) pp.248-254, ISSN 0003-2697 
Brück, A., Kurki, T., Kaasinen, V., Vahlberg, T. \& Rinne, J.O. (2004). Hippocampal and prefrontal atrophy in patients with early non-demented Parkinson's disease is related to cognitive impairment. Journal of Neurology, Neurosurgery E Psychiatry, Vol.75, No.10, (October 2004), pp.1467-1469. ISSN 0022-3050

Chai SY, Yeatman HR, Parker MW, Ascher DB, Thompson PE, Mulvey HT. \& Albiston, A.L. (2008), Development of cognitive enhancers based on inhibition of insulinregulated aminopeptidase. BMC Neuroscience, Vol. 9, Suppl. 2, (December 2008), pp. S14, ISSN 1471-2202

Cubo, E., Martin, P.M., Martin-Gonzalez, J.A., Rodriguez-Blazquez, C. \& Kulisevsky, J. ELEP Group Members. (2010). Motor laterality asymmetry and nonmotor symptoms in Parkinson's disease. Movement Disorders, Vol.25, No.1, (January 2010), pp.70-75. ISSN 0885-3185

Diana, G. (2002). Does hypertension alone lead to cognitive decline in spontaneously hypertensive rats? Behavioural Brain Research, Vol.134, No.1-2, (August 2002), pp. 113-121. ISSN 0166-4328

Djaldetti, R., Ziv, I. \& Melamed, E. (2006). The mystery of motor asymmetry in Parkinson's disease. Lancet Neurology, Vol. 5, No.9, (September 2006), pp.796-802. ISSN 1474-4422

Dorsey, E.R., Constantinescu, R., Thompson, J.P., Biglan, K.M., Holloway, R.G., Kieburtz, K., Marshall, F.J., Ravina, B.M., Schifitto, G., Siderowf, A. \& Tanner, C.M. (2007). Projected number of people with Parkinson disease in the most populous nations, 2005 through 2030. Neurology, Vol.68, No.5, (January 2007), pp.384-386, ISSN 0028-3878

Farina, E., Cappa, S.F., Polimeni, M., Magni, E., Canesi, M., Zecchinelli, A., Scarlato, G. \& Mariani, C. (1994). Frontal dysfunction in early Parkinson's disease, Acta Neurologica Scandinavica, Vol.90, No.1, (July 1994) pp. 34-38. ISSN 0365-5598

Farkas, E., De Jong, G.I., Apró, E., De Vos, R.A., Steur, E.N. \& Luiten, P.G. (2000). Similar ultrastructural breakdown of cerebrocortical capillaries in Alzheimer's disease, Parkinson's disease, and experimental hypertension. What is the functional link? Annals of the New York Academy of Sciences. Vol.903, (April 2000) pp.72-82. ISSN 0077-8923

Fernando, R.N., Lara, J., Albiston, A.L. \& Chai, S.Y. (2005). Distribution and cellular localization of insulin-regulated aminopeptidase in the rat central nervous system. Journal of Comparative Neurology, Vol.487, No.4, (July 2005), pp. 372-90. ISSN 0021-9967

Gard, P.R. (2008). Cognitive-enhancing effects of angiotensin IV. BMC Neuroscience, Vol.9, Suppl.2, (December 2008) pp. S15. ISSN 1471-2202

George, J.L., Mok, S., Moses, D., Wilkins, S., Bush, A.I., Cherny, R.A. \& Finkelstein, D.I. (2009). Targeting the progression of Parkinson's disease. Current Neuropharmacology, Vol.7, No.1, (Mars 2009) pp.9-36. ISSN 1570-159X

Glick, S.D., Jerussi, T.P., Water, D.H. \& Green JP. (1974), Amphetamine-induced changes in striatal dopamine and acetylcholine levels and relationship to rotation (circling behavior) in rats. Biochemical Pharmacology. Vol.23, No.22, (November 1974), pp. 3223-3225, ISSN 0006-2952.

Glick, S.D. (1983). Cerebral lateralization in the rat and tentative extrapolations to man. In: Hemisyndromes: Psychobiology, Neurology, Psychiatry. M. Myslobodsky (Ed.) pp. 726., ISBN 0125124600, Academic Press, London.

Gülpinar, M.A. \& Yegen, B.C. (2004). The physiology of learning and memory: role of peptides and stress. Current Protein and Peptide Science Vol.5, No.6, (December 2004), pp. 457-473, ISSN 1098-5522

Henderson, J.M., Watson, S., Halliday, G.M., Heinemann, T. \& Gerlach, M. (2003). Relationships between various behavioural abnormalities and nigrostriatal 
dopamine depletion in the unilateral 6-OHDA-lesioned rat. Behavioural Brain Research, Vol.139, No.1-2, (February 2003) pp. 105-113. ISSN 0166-4328

Huber, S.J., Miller, H., Bohaska, L., Christy, J.A. \& Bornstein, R.A. (1992). Asymmetrical cognitive differences associated with hemiparkinsonism. Archives of Clinical Neuropsychology, Vol.7, No.6, (November 1992), pp. 471-80. ISSN 0887-6177

Insel, T.R. (2010). The challenge of translation in social neuroscience: a review of oxytocin, vasopressin, and affiliative behavior. Neuron, Vol.65 No.6 (Mars 2010), pp.768-779, ISSN 0896-6273.

Jolicoeur, F.B. \& Rivest, R. (1992). Rodent model of Parkinson's disease, In: Neuromethods 21, Animal Models of Neurological Disease I, A.A. Boulto, G.B. Bakerand a R.F. Butterworth (Eds.). 135-158, Humana Press, ISBN 0-89603-198-5, Totowa, New Jersey

Lang, A.E. \& Obeso, J.A. (2004), Challenges in Parkinson's disease: restoration of the nigrostriatal dopamine system is not enough. Lancet Neurology, Vol.3, No.5, (May 2004), pp. 309-16, ISSN 1474-4422

Neumann, I.D. (2009). The advantage of social living: brain neuropeptides mediate the beneficial consequences of sex and motherhood. Frontiers in Neuroendocrinology, Vol. 30, No.4, (October 2009), pp. 483-496, ISSN 0091-3022

Ouimet, A.J., Gawronski, B. \& Dozois, D.J. (2009). Cognitive vulnerability to anxiety: A review and an integrative model. Clinical Psychology Review, Vol.29, No.6, (August 2009), pp. 459-470, ISSN 0272-7358

Paxinos, G. \& Watson C. (1998). The rat brain in stereotaxic coordinates, Academic Press, 4th Ed. ISBN 13: 9780123742438, London, England.

Piacentini, S., Versaci, R., Romito, L., Ferré, F. \& Albanese A. (2010) Behavioral and personality features in patients with lateralized Parkinson's disease. European Journal of Neurology. (December 2010) [Epub ahead of print], ISSN 1468-1331

Ramírez, M., Prieto, I., Vives, F., de Gasparo, M. \& Alba, F. (2004). Neuropeptides, neuropeptidases and brain asymmetry. Current Protein and Peptide Science, Vol.5, No.6, (December 2004), pp. 497-506. ISSN 1098-5522

Robinson, T.E., Noordhoorn, M., Chan, E.M., Mocsary, Z., Camp, D.M, \& Whishaw, I.Q. (1994). Relationship between asymmetries in striatal dopamine release and the direction of amphetamine-induced rotation during the first week following a unilateral 6-OHDA lesion of the substantia nigra. Synapse, (May 1994)Vol. 17, No.1, pp. 16-25, ISSN 0887-4476

Russell, V.A. (2007). Reprint of "Neurobiology of animal models of attention-deficit hyperactivity disorder". Journal of Neuroscience Methods, (November 2007), Vol.166, No.2, pp. I-XIV, ISSN 1872-678X

Sánchez, F., Gómez-Villalobos, M. de J., Juarez, I., Quevedo, L. \& Flores, G. (2011). Dendritic morphology of neurons in medial prefrontal cortex, hippocampus, and nucleus accumbens in adult SH rats. Synapse. (Mars 2011) Vol.65, No.3, (Mars 2011), pp. 198206. ISSN 0887-4476

Shapiro, R.M., Glick, S.D. \& Hough, L.B. (1986). Striatal dopamine uptake asymmetries and rotational behavior in unlesioned rats: revising the model? Psychopharmacology (Berl), Vol.89, No.1, pp.25-30, ISSN: 0033-3158.

Shaw, P., Lalonde, F., Lepage, C., Rabin, C., Eckstrand, K., Sharp, W., Greenstein, D., Evans, A., Giedd, J.N. \& Rapoport, J. (2009). Development of cortical asymmetry in typically developing children and its disruption in attention-deficit/hyperactivity disorder. Archives of General Psychiatry, Vol.66, No.8, (August 2009), pp.888-896, ISSN 0003-990x

Stragier, B., Demaegdt, H., De Burdel, D., Smolders, I., Sarre, S., Vauquelin, G., Ebinger, G., Micote, Y. \& Vanderheyden, P. (2007), Involvement of insulin-regulated 
aminopeptidase and/or aminopeptidase $\mathrm{N}$ in the angiotensin IV-induced effect on dopamine release in the striatum of the rat. Brain Research, Vol. 1131 No.1 (February 2007) pp. 97-105. ISSN 00068993.

Stragier, B., De Bundel, D., Sarre, S., Smolders, I., Vauquelin, G., Dupont, A., Michotte, Y. \& Vanderheyden, P. (2008). Involvement of insulin-regulated aminopeptidase in the effects of the renin-angiotensin fragment angiotensin IV: a review. Heart Failure Reviews, Vol.13, No.3, (September 2008), pp. 321-37. ISSN 1382-4147

Sullivan, R.M. \& Brake, W.G. (2003). What the rodent prefrontal cortex can teach us about attention-deficit/hyperactivity disorder: the critical role of early developmental events on prefrontal function. Behavioural Brain Research, Vol.146, No.1-2, (November 2003) pp. 43-55, ISSN 0166-4328

Sullivan, R.M. (2004). Hemispheric asymmetry in stress processing in rat prefrontal cortex and the role of mesocortical dopamine. Stress, Vol.7, No.2, (June 2004), pp. 131-143. ISSN 1025-3890

Tsujimoto, M., Mizutani, S., Adachi, H., Kimura, M., Nakazato, H. \& Tomoda, Y. (1992). Identification of human placental leucine aminopeptidase as oxytocinase. Archives of Biochemistry and Biophysics, Vol.292, No.2, (February 1992), pp. 388-392. ISSN 0003-9861

Tzschentke, T.M. (2000). The medial prefrontal cortex as a part of the brain reward system. Amino Acids, Vol.19, No.1, pp. 211-219, ISSN 0939-4451

Ungerstedt, U. (1971). Adipsia and aphagia after 6-hydroxydopamine induced degeneration of the nigro-striatal dopamine system. Acta Physiologica Scandinavica Vol.367, pp. 95-122, ISSN 0001-6772

Vallesi, A., McIntosh, A.R., Kovacevic, N., Chan, S.C. \& Stuss, D.T. (2010). Age effects on the asymmetry of the motor system: evidence from cortical oscillatory activity. Biological Psychology, (October 2010) Vol.85, No.2, pp.213-218. ISSN 0301-0511

Veenema, A.H. \& Neumann, I.D. (2008). Central vasopressin and oxytocin release: regulation of complex social behaviours. Progress in Brain Research Vol.170 pp. 261276. ISSN 0079-6123

Viggiano, D., Ruocco, L.A., Arcieri, S. \& Sadile, A.G. (2004). Involvement of norepinephrine in the control of activity and attentive processes in animal models of attention deficit hyperactivity disorder. Neural Plasticity. Vol.11, No.1-2, pp.133-149. ISSN 1687-5443

Vinyoles, E., De la Figuera. M. \& Gonzalez-Segura, D. (2008). Cognitive function and blood pressure control in hypertensive patients over 60 years of age: COGNIPRES study. Current Medical Research and Opinion. Vol.24, No.12, (December 2008), pp.3331-3339, ISSN 0300-7995

Wenk, G.L. (1989) An hypothesis on the role of glucose in the mechanism of action of cognitive enhancers. Psychopharmacology Vol.99, No,4, pp. 431-438. ISSN 0033-3158

$\mathrm{Xu}$, Z.C., Ling, G., Sahr, R.N. \& Neal-Beliveau BS. (2005). Asymmetrical changes of dopamine receptors in the striatum after unilateral dopamine depletion. Brain Research, (Mars 2005), Vol.1038, No.2, pp.163-70, ISSN: 0006-8993

Xu, Y., Valentino, D.J., Scher, A.I., Dinov, I., White, L.R., Thompson, P.M., Launer, L.J. \& Toga, A.W. (2008). Age effects on hippocampal structural changes in old men: the HAAS. Neuroimage, Vol.40, No.3, (April 2008) pp. 1003-1015. ISSN 1053-8119

Zgaljardic, D.J., Borod, J.C., Foldi, N.S., Mattis, P.J., Gordon, M.F., Feigin, A. \& Eidelberg, D. (2006). An examination of executive dysfunction associated with frontostriatal circuitry in Parkinson's disease. Journal of Clinical and Experimental Neuropsychology Vol.28, No.7, (October 2006), pp. 1127-1144. ISSN 1380-3395

Zimmerberg, B., Glick, S.D. \& Jerussi, T.P. (1974) Neurochemical correlate of a spatial preference in rats. Science. Vol.185, No.151, (August 1974), pp. 623-5, ISSN 0036-8075. 


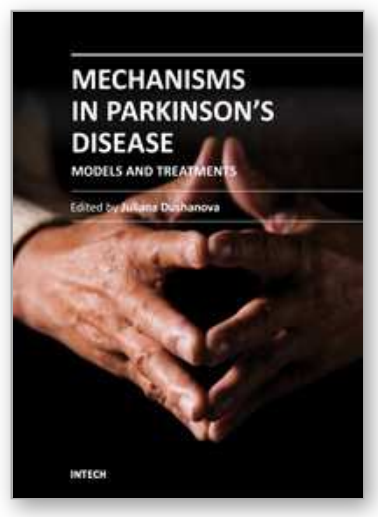

\author{
Mechanisms in Parkinson's Disease - Models and Treatments \\ Edited by Dr. Juliana Dushanova
}

ISBN 978-953-307-876-2

Hard cover, 582 pages

Publisher InTech

Published online 08, February, 2012

Published in print edition February, 2012

Parkinson's disease (PD) results primarily from the death of dopaminergic neurons in the substantia nigra. Current PD medications treat symptoms; none halt or retard dopaminergic neuron degeneration. The main obstacle to developing neuroprotective therapies is a limited understanding of the key molecular mechanisms that provoke neurodegeneration. The discovery of PD genes has led to the hypothesis that misfolding of proteins and dysfunction of the ubiquitin-proteasome pathway are pivotal to PD pathogenesis. Previously implicated culprits in PD neurodegeneration, mitochondrial dysfunction, and oxidative stress may also act in part by causing the accumulation of misfolded proteins, in addition to producing other deleterious events in dopaminergic neurons. Neurotoxin-based models have been important in elucidating the molecular cascade of cell death in dopaminergic neurons. PD models based on the manipulation of PD genes should prove valuable in elucidating important aspects of the disease, such as selective vulnerability of substantia nigra dopaminergic neurons to the degenerative process.

\title{
How to reference
}

In order to correctly reference this scholarly work, feel free to copy and paste the following:

Manuel Ramírez, Inmaculada Banegas, Ana Belén Segarra, Rosemary Wangesteen, Marc de Gasparo, Raquel Durán, Francisco Vives, Antonio Martínez, Francisco Alba and Isabel Prieto (2012). Bilateral Distribution of Oxytocinase Activity in the Medial Prefrontal Cortex of Spontaneously Hypertensive Rats with Experimental Hemiparkinsonism, Mechanisms in Parkinson's Disease - Models and Treatments, Dr. Juliana Dushanova (Ed.), ISBN: 978-953-307-876-2, InTech, Available from:

http://www.intechopen.com/books/mechanisms-in-parkinson-s-disease-models-and-treatments/bilateraldistribution-of-oxytocinase-activity-in-the-medial-prefrontal-cortex-of-spontaneously-hype

\section{INTECH}

open science | open minds

\author{
InTech Europe \\ University Campus STeP Ri \\ Slavka Krautzeka 83/A \\ 51000 Rijeka, Croatia \\ Phone: +385 (51) 770447 \\ Fax: +385 (51) 686166 \\ www.intechopen.com
}

\author{
InTech China \\ Unit 405, Office Block, Hotel Equatorial Shanghai \\ No.65, Yan An Road (West), Shanghai, 200040, China \\ 中国上海市延安西路65号上海国际贵都大饭店办公楼 405 单元 \\ Phone: +86-21-62489820 \\ Fax: +86-21-62489821
}


(C) 2012 The Author(s). Licensee IntechOpen. This is an open access article distributed under the terms of the Creative Commons Attribution 3.0 License, which permits unrestricted use, distribution, and reproduction in any medium, provided the original work is properly cited. 